\title{
Tumors of the Central Nervous System in Children and Adolescents
}

\author{
Michael C. Frühwald, Stefan Rutkowski
}

\section{SUMMARY}

Background: Multimodal treatment approaches for children with tumors of the central nervous system (CNS) have markedly contributed to improved survival. Before 1970 , the survival rate among children with medulloblastoma, the most common malignant CNS tumor in children, was about $20 \%$. At present, in contrast, cure can be achieved in more than $75 \%$ of children with a favorable constellation of risk factors. In this review article for clinicians, we give an overview of the current understanding of the pathology, presenting manifestations, early diagnosis, and treatment of CNS tumors in children and adolescents.

Methods: We report the research findings of the German Treatment Network "HIT" and selectively review the pertinent literature.

Results: Treatment-optimizing clinical trials have improved survival from all types of CNS tumors in children and adolescents. Biological features of the tumors now serve as the basis for improved stratification for multimodal, riskadapted treatment. Targeted biological strategies are being developed. Difficulties remain, however, in the care of infants with CNS tumors and in the treatment of metastatic disease, tumors of certain histological types, and tumors in certain anatomical sites. Many of the affected children suffer from late effects of their disease and its treatment that can irreversibly impair their development.

Conclusion: Children with a suspected or confirmed diagnosis of brain tumor should be referred early to a center with the relevant experience. Standardized diagnostic and therapeutic methods have markedly improved the chance of cure. Current research on molecular signaling pathways seems likely to lead to the development of new treatments, particularly for tumors currently associated with lower rates of survival. The long-term side effects of treatment must be systematically monitored so that they can be avoided in future, and so that appropriate support measures can be provided to the affected children.

\section{- Cite this as:}

Frühwald MC, Rutkowski S: Tumors of the central nervous system in children and adolescents. Dtsch Arztebl Int 2011; 108(22): 390-7. DOI: 10.3238/arztebl.2011.0390

\footnotetext{
I. Klinik für Kinder und Jugendliche, Klinikum Augsburg:
} Prof. Dr. Dr. med. Frühwald

Klinik für Pädiatrische Hämatologie und Onkologie, Universitätsklinikum Hamburg-Eppendorf: Prof. Dr. med. Rutkowski $\mathrm{n}$ the 10 -year period from 1998 to 2007 , a total of

4140 children under the age of 15 years were diagnosed in Germany as having a tumor of the central nervous system (CNS). This represents an incidence of around 400 new cases annually ( kinderkrebsregister@imbei.uni-mainz.de). Infants are just as frequently affected as older children. The histological spectrum of CNS tumors in children and adolescents differs from that in adults. Astrocytomas and embryonal tumors are the most common entities, followed by ependymomas (Table 1). Malignant tumors (WHO grade III and IV) grow invasively and tend to metastasize along the cerebrospinal fluid (CSF) pathways. Grade I and II tumors may also disseminate (1). Metastasis beyond the CNS has been described but is rare.

\section{Symptoms}

More than half of all CNS tumors in children and adolescents are found in the posterior cranial fossa or in the brain stem. A tumor in this region may obstruct CSF drainage and thus increase the intracranial pressure. This effect is aggravated by the volume of the tumor itself and the peritumoral edema. The primary symptoms are headache, nausea, and vomiting in the morning before intake of food. The nausea often improves during the course of the day, and the headache may become less severe after vomiting (hyperventilation, $\mathrm{pCO}_{2}$ decreases, vasoconstriction, intracranial pressure decreases). Half the children with brain tumors initially show no signs of increased intracranial pressure (2) (Table 2).

Papilledema is characteristic for raised intracranial pressure and indicates diagnostic imaging. Particularly in neonates and infants with an open fontanelle, however, this symptom complex may not be present. Instead, the symptoms in this group of patients include macrocephaly, changes in behavior, failure to thrive, or primary neurological symptoms such as torticollis or convergent strabismus (cranial nerve VI palsy). Neonates and infants sometimes display symptoms of hyperarousal such as loud crying for no apparent reason. "Localizing" symptoms may indicate which neural structures are involved and yield limited information as to tumor type (Table 2). Early diagnosis increases the likelihood that the tumor will be operable. Particularly in the case of low-grade tumors, years may pass before the headaches, macrocephaly, and failure to thrive are joined by other symptoms, e.g. endocrine deficits or 
visual impairment. Persisting non-specific symptoms should prompt examination by a physician experienced in CNS tumors. Timely investigation of persisting general and/or local symptoms can facilitate early diagnosis.

The following signs and symptoms may point to medullary compression by a spinal tumor: pain, paresthesia, sensory disorders, asthenia, disorders of the autonomous nervous system, and ataxia (compression of spinocerebellar pathways).

\section{Etiology, molecular genetics, and clinical syndromes}

Most brain tumors in children are sporadic, that is to say they arise with no discernable familial or environmental cause. Known molecular target structures and the compounds used to influence them are listed in eTable 1 . Fewer than $5 \%$ of pediatric CNS tumors occur in the framework of defined familial syndromes (eTable 2) $(3,4)$.

\section{Staging and diagnostic imaging}

Magnetic resonance imaging (MRI) is superior to computed tomography (CT) for evaluation of the anatomy. In infants, sonography through the open fontanelle may reveal signs of hydrocephalus, cerebral edema, hemorrhage, or mass effect. If at all possible, MRI or CT should be carried out before lumbar puncture (cave: herniation). In the case of malignant tumors, spinal MRI to detect metastases should ideally be performed before surgery, otherwise together with the early postoperative follow-up imaging within 48 to $72 \mathrm{~h}$. The typical neuroradiological appearances of various brain tumors in children are shown in Figure 1.

Modern imaging procedures are a useful diagnostic tool, but histological confirmation remains necessary in the majority of case. The internationally recognized standard procedures include MRI with plain and contrast-enhanced $\mathrm{T} 1$ and $\mathrm{T} 2$ sequences, or alternatively MRI-based fluid-attenuated inverse recovery (FLAIR), and diffusion-weighted imaging (DWI) (5). Functional modalities such as amino acid PET are used to assess the treatment response and the biological activity of residual tumor tissue, to select a biopsy site, and to delimit the tumor from normal brain tissue (6).

There are no standard criteria for the demonstration of tumor cells in CSF. Cytological and immunohistochemical demonstration of tumor cells (individual cells or clusters) in CSF obtained 14 days after operation is considered significant and is relevant for treatment stratification, particularly in the case of medulloblastoma (stage M1) (Figure 2).

Chang's classification for the staging of medulloblastoma has been adopted for other CNS tumors (Box).

In midline supratentorial tumors, elevation of beta HCG (human chorionic gonadotrophin) and/or alpha fetoprotein in serum and CSF may point to a secreting germ-cell tumor. If the typical signs are also seen on imaging, histological confirmation may be unnecessary.

\section{TABLE 1}

\section{CNS tumors in childhood and adolescence*}

\begin{tabular}{|c|c|c|}
\hline Entity & WHO grade & Frequency ${ }^{* 2}$ \\
\hline \multicolumn{3}{|l|}{ Astrocytic tumors } \\
\hline $\begin{array}{l}\text { - Pilocytic astrocytoma } \\
\text { - Pilomyxoid astrocytoma }\end{array}$ & I & $\sim 30 \%$ \\
\hline $\begin{array}{l}\text { - Diffuse astrocytoma } \\
\text { - Pleomorphic xanthoastrocytoma } \\
\text { - Anaplastic astrocytoma } \\
\text { - Glioblastoma }\end{array}$ & $\begin{array}{l}\text { II } \\
\text { II } \\
\text { III } \\
\text { IV }\end{array}$ & $\begin{array}{l}\sim 12 \% \\
<1 \% \\
\sim 2 \% \\
\sim 3 \%\end{array}$ \\
\hline \multicolumn{3}{|l|}{ Oligodendroglial tumors } \\
\hline $\begin{array}{l}\text { - Oligodendroglioma } \\
\text { - Anaplastic oligodendroglioma }\end{array}$ & $\begin{array}{l}\text { II } \\
\text { III }\end{array}$ & $\sim 1,5 \%$ \\
\hline \multicolumn{3}{|l|}{ Ependymal tumors } \\
\hline $\begin{array}{l}\text { - Subependymoma } \\
\text { - Myxopapillary ependymoma } \\
\text { - Ependymoma } \\
\text { - Anaplastic ependymoma }\end{array}$ & $\begin{array}{l}\text { I } \\
\text { II } \\
\text { III }\end{array}$ & $\sim 9 \%$ \\
\hline \multicolumn{3}{|l|}{ Tumors of choroid plexus } \\
\hline $\begin{array}{l}\text { - Plexuspapilloma } \\
\text { - Atypical plexus papilloma } \\
\text { - Plexus carcinoma }\end{array}$ & $\begin{array}{l}\text { I } \\
\text { II } \\
\text { III }\end{array}$ & $\sim 2 \%$ \\
\hline \multicolumn{3}{|l|}{ Neuronal and mixed neuronal-glial tumors } \\
\hline $\begin{array}{l}\text { - Ganglioglioma } \\
\text { - Anaplastic ganglioglioma } \\
\text { - Dysembryoplastic neuroepithelial tumor (DNET) } \\
\text { - Neurocytoma }\end{array}$ & $\begin{array}{l}\text { II } \\
\text { III }\end{array}$ & $\sim 2.5 \%$ \\
\hline \multicolumn{3}{|l|}{ Pineal tumors } \\
\hline $\begin{array}{l}\text { - Pineocytoma } \\
\text { - Pineoblastoma } \\
\text { - Papillary tumor of pineal region }\end{array}$ & $\begin{array}{l}\text { I } \\
\text { IV } \\
\text { II/III }\end{array}$ & $\sim 1.3 \%$ \\
\hline \multicolumn{3}{|l|}{ Embryonal tumors } \\
\hline $\begin{array}{l}\text { - Medulloblastoma } \\
\text { - Supratentorial primitive neuroectodermal tumor } \\
\text { (cPNET) } \\
\text { - Atypical teratoid/rhabdoid tumor } \\
\text { (AT/RT) }\end{array}$ & $\begin{array}{l}\text { IV } \\
\text { IV } \\
\text { IV }\end{array}$ & $\begin{array}{l}\sim 20 \% \\
\sim 3 \% \\
\sim 1 \%\end{array}$ \\
\hline \multicolumn{3}{|l|}{ Tumors of sellar region } \\
\hline Craniopharyngioma & I & $\sim 5 \%$ \\
\hline \multicolumn{3}{|l|}{ Tumors of peripheral nerves } \\
\hline $\begin{array}{l}\text { - Schwannoma } \\
\text { - Neurofibroma } \\
\text { - Malignant peripheral nerve sheath tumor (MPNST) }\end{array}$ & IIIIV & $\sim 1 \%$ \\
\hline \multicolumn{3}{|l|}{ Meningeal tumors } \\
\hline $\begin{array}{l}\text { - Meningeoma } \\
\text { - Atypical meningioma } \\
\text { - Anaplastic meningioma } \\
\text { - Hemangiopericytoma } \\
\text { - Anaplastic hemangiopericytoma } \\
\text { - Hemangioblastoma }\end{array}$ & $\begin{array}{l}\text { I } \\
\text { II } \\
\text { III } \\
\text { II } \\
\text { III } \\
\text { I }\end{array}$ & $\sim 1.2 \%$ \\
\hline \multicolumn{3}{|l|}{ Germ cell tumors } \\
\hline $\begin{array}{l}\text { - Teratoma } \\
\text { - Choriocarcinoma } \\
\text { - Germinoma } \\
\text { - Embryonal carcinoma } \\
\text { - Yolk sac tumor }\end{array}$ & & $\sim 3 \%$ \\
\hline
\end{tabular}


TABLE 2

Cardinal symptoms of CNS tumors in children and adolescents

\begin{tabular}{|c|c|}
\hline Cause & Cardinal symptom \\
\hline Elevated intracranial pressure & $\begin{array}{l}\text { Vomiting (despite empty stomach), headache, per- } \\
\text { sonality changes, cranial nerve VI palsy, papille- } \\
\text { dema and visual impairment, sunset phenomenon, } \\
\text { macrocephaly }\end{array}$ \\
\hline Cerebellar tumor & $\begin{array}{l}\text { Unsteady gait, scanning speech, ataxia, nystag- } \\
\text { mus, intention tremor, dysdiadochokinesis }\end{array}$ \\
\hline Brain stem tumor/infiltration & $\begin{array}{l}\text { Horizontal ophthalmoplegia, cranial nerve palsies, } \\
\text { spastic palsies, long tract signs }\end{array}$ \\
\hline $\begin{array}{l}\text { Cerebellopontine } \\
\text { tumor/extension }\end{array}$ & Facial paralysis, hearing loss, torticollis \\
\hline Cerebral hemispheric tumor & $\begin{array}{l}\text { Cerebral seizures (e.g., complex partial seizures), } \\
\text { pareses, paralyses, sensory impairments }\end{array}$ \\
\hline $\begin{array}{l}\text { Suprasellar tumor/chiasma/ } \\
\text { hypothalamus tumors }\end{array}$ & $\begin{array}{l}\text { Vision loss, narrowing of visual field, } \\
\text { nystagmus }\end{array}$ \\
\hline $\begin{array}{l}\text { Tumor of hypophyseal and } \\
\text { hypothalamic region }\end{array}$ & $\begin{array}{l}\text { Short stature, diabetes insipidus, disordered puber- } \\
\text { tal development, eating disorders }\end{array}$ \\
\hline Diencephalic tumors/infiltration & $\begin{array}{l}\text { Diencephalic syndrome: cachexia in infants who } \\
\text { sometimes appear euphoric }\end{array}$ \\
\hline Pineal/midbrain tumor & Parinaud syndrome with vertical ophthalmoplegia \\
\hline Spinal tumors and metastases & $\begin{array}{l}\text { Back pain, scoliosis, transverse symptoms, pyrami- } \\
\text { dal tract signs, but also flaccid paralysis }\end{array}$ \\
\hline
\end{tabular}

\section{Emergency care}

Treatment to counteract elevated intracranial pressure must be initiated immediately after detection of a CNS tumor, in parallel with diagnostic procedures. The patient should not lie flat, and, particularly important, dexamethasone should be administered (initially $1 \mathrm{mg}$ / $\mathrm{kg}$ to a maximum of $50 \mathrm{mg}$; then 0.5 to $1.5 \mathrm{mg} / \mathrm{kg} / \mathrm{day}$; from the $3 \mathrm{rd}$ to 5 th day, or when the cerebral pressure crisis is over, $0.15 \mathrm{mg} /$ day; then taper depending on the clinical situation). Patients on artificial respiration should be hyperventilated. Rotation of the head should be avoided (jugular drainage!).

External CSF drainage serves as a bridging measure until definitive tumor removal can be carried out. Early resection is preferable as long as the risk is acceptable, and near-total tumor extirpation can be anticipated without significant neurological damage.

Steroids represent the treatment of choice for spinal masses. Neurosurgery is indicated in the case of medullary compression, particularly in previously irradiated segments of the spinal column, radio- and chemoresistant tumors, and tumors characterized by biopsy. Surgical treatment comprises laminectomy and fixation. Because of the potentially catastrophic neurological consequences (quadriplegia!) and severe pain, radiotherapy is also indicated for palliation in radiosensitive tumors.
Cerebral seizures are often the first symptom in adolescents and in supratentorial tumors (infratentorial tumors: $1 \%$ to $6 \%$ ). The mortality rate in childhood is $3 \%$ to $5 \%$. The treatment comprises general measures (airways!, oxygen, i.v. access etc.) and antiepileptics (7).

\section{Neurosurgery}

The goal of neurosurgery is ideally complete microsurgical removal of the tumor. However, the potential operation-associated morbidity must always be taken into consideration. Despite improvements in neuroradiological procedures, the tumor type remains unclear, and potential differential diagnoses include abscesses, circumscribed hemorrhages, and cysts. Therefore, histopathological examination is generally required for definitive diagnosis. Exceptions where the typical imaging appearance suffices are:

- Diffuse-intrinsic pontine glioma

- Tumor marker-positive germ-cell tumors

- Optic pathway glioma in neurofibromatosis 1 (NF1)

- Vestibular schwannoma in NF2.

Because imaging artifacts increase just a few days after surgery, early postoperative imaging is important not only for detection of residual tumor and to determine the appropriate adjuvant therapy, but also for comparison with later follow-up findings and for discussion of further treatment (e.g. second-look surgery).

\section{The HIT Treatment Network}

Over $90 \%$ of children with CNS tumors diagnosed in Germany are included in treatment optimization studies.

The HIT Treatment Network of the German Society for Pediatric Oncology and Hematology (Gesellschaft für Pädiatrische Onkologie und Hämatologie, GPOH) combines the study centers for all tumor entities with reference centers for neuropathology, neuroradiology, CSF diagnosis, and radiotherapy. The goal is nationwide implementation of multimodal treatment optimization studies with quality-controlled interdisciplinary standards for diagnosis, surgery, irradiation, and chemotherapy. Treatment optimization studies are the gold standard for patient care in pediatric oncology (8).

\section{Low-grade gliomas}

Low-grade gliomas (LGG) are an extremely heterogeneous group of diseases. Complete resection alone may be curative, but is possible only in a few locations (e.g., the cerebellum), and then in only $65 \%$ to $80 \%$ of cases. Postoperative indications for treatment include new or worsened neurological deficits and signs of tumor progression on imaging (prevention of neurological damage). Adjuvant therapy is also indicated in the case of significant impairment or worsening of vision. According to the protocol of the SIOP LGG 2004 study, irradiation is recommended only for children aged at least 8 years; younger patients are usually treated primarily by chemotherapy. 


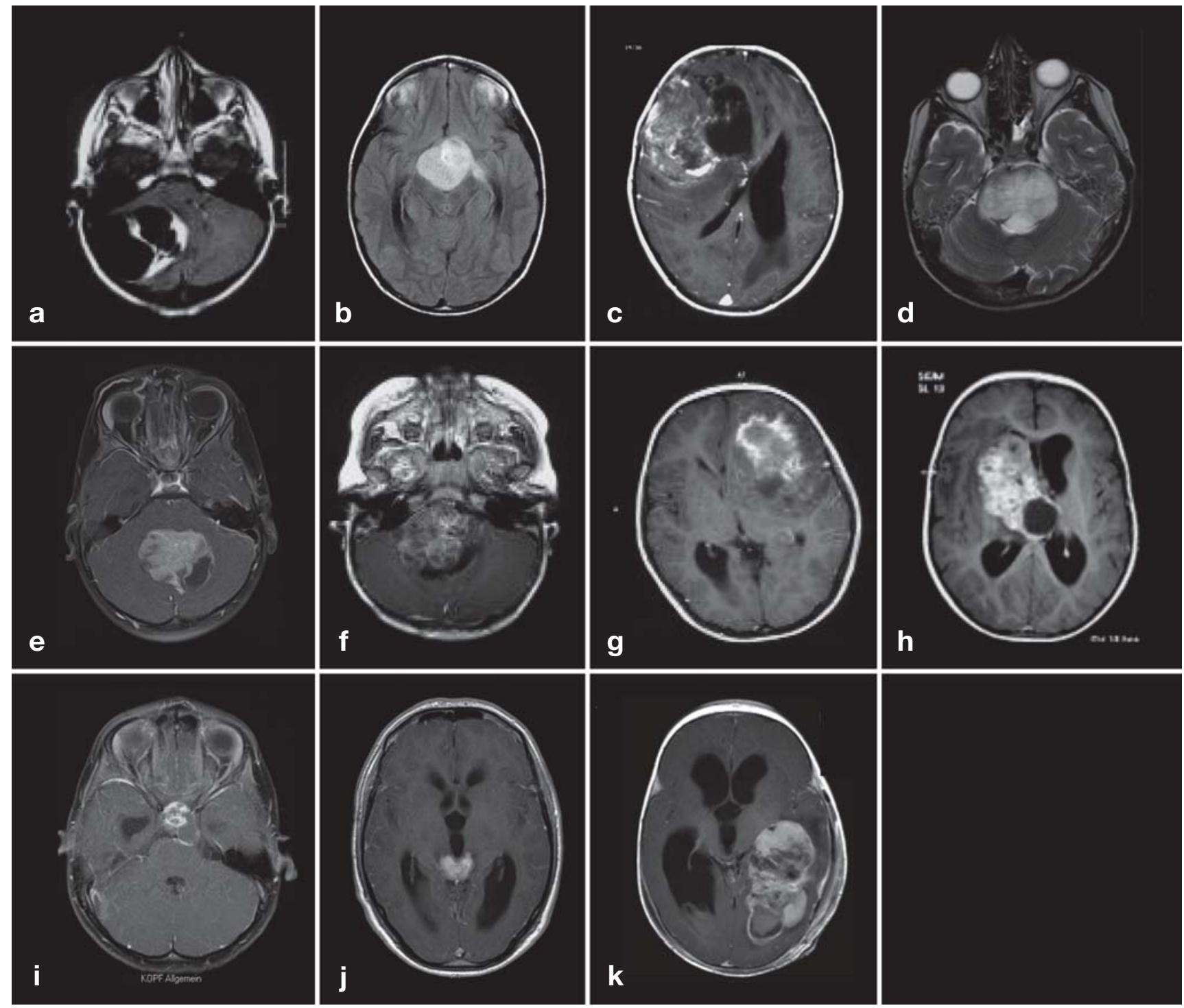

Figure 1: Typical imaging characteristics of selected CNS tumors of childhood and adolescence

a) Pilocytic astrocytoma (CT): Hypo-or isodense, calcification demonstrated in ca. 10\% of cases, often cystic. T1: Positive with contrast medium; T2: hyperintense, whereas fibrillary astrocytoma usually does not take up contrast medium (CM).

b) Optic pathway glioma (FLAIR, axial): differential diagnoses germ cell tumor (GCT), craniopharyngioma. T2: Hyperintense; T1: glioma shows hyperintensity of posterior lobe of hypophysis, while craniopharyngioma and GCT often do not.

c) Glioblastoma (T1, axial, CM+). CT: Inhomogeneous, peritumoral edema; T1: garland-like CM uptake; T2: inhomogeneous, pronounced zone of edema.

d) Pontine glioma (T2, axial). T1: Variable contrast enhancement. $>50 \%$ of cross-sectional area, main tumor volume in pons, basilar artery typically enclosed.

e) Medulloblastoma (T1, axial, CM+). CT: Hyperdense, $90 \%$ in vermis, 10\% in hemispheres; T1: iso- to hypointense, variable CM uptake; T2: variable signal intensity, often hypointense, inhomogeneous.

f) Anaplastic ependymoma (T1, axial, CM+). CT: Inhomogeneous, hyperdense (isodense), 50\% calcifications, often cysts; plastic growth, e.g., protrusion into the foramen magnum; $\mathrm{T} 1$ mostly strong CM uptake; T2: as for medulloblastoma.

g) Cerebral PNET (T1, axial, CM+). CT: Mostly hyperdense, relatively weak CM uptake, inhomogeneous enhancement; T1: variable signal intensity; T2: hypointense, paradoxically little perifocal edema, clear demarcation.

h) AT/RT (T1, axial, CM+). CT: Hyperdense, changeable CM uptake, sometimes cysts (necroses) with hemorrhaging; T1: iso- to hypointense, variable CM uptake; T1 and T2: variable signal; cysts/necroses: pronounced edema.

i) Craniopharyngioma (T1, axial, CM+). CT: Calcifications, cysts; T1: cysts with/without solid components, hypo- to hyperintense (colloid); T2: cysts hyperintense, calcifications hypointense.

j) Germinoma (T1, axial, $\mathrm{CM}+$ ). CT: Hyperdense, calcification demonstrated in some areas; MRI: distinct homogeneous CM uptake, small cysts if any at all, physiological hyperintensity of posterior lobe of hypophysis no longer present.

k) Plexus carcinoma (T1, axial, CM+). CT: Calcifications, tumor located in plexus, contrast enhancement; $\mathrm{T} 1$ : strong gadolinium enhancement, nodular; T2: usually hypointense. 
Figure 2: Morphology of metastatic tumor cells in CSF (cytospun samples, Pappenheim staining).

a) Cluster of tumor cells in medulloblastoma. The cells display an altered nucleus/ plasma ratio and show nucleoli; they are frequently arranged in nests and homogeneous. Morphologically, individual cells are often indistinguishable from the blasts seen in lymphoma or leukemia.

b) Anaplastic ependymoma. The cells are mostly smaller than the medulloblastoma cells; they often display indentations of the nuclei and finer cytoplasm.

c) Cell nest in AT/RT. Cells of AT/RT are characterized by marked heterogeneity. Some cytoplasmic vacuoles are seen, but the primary impression is of inhomogeneous, irregular nuclear chromatin.

d) Two germinoma cells flanked by cells of the monocyte/macrophage lineage and a lymphocyte. The tumor cells are vastly larger than the normal blood cells and show a characteristic cytoplasmic vacuolar margin.

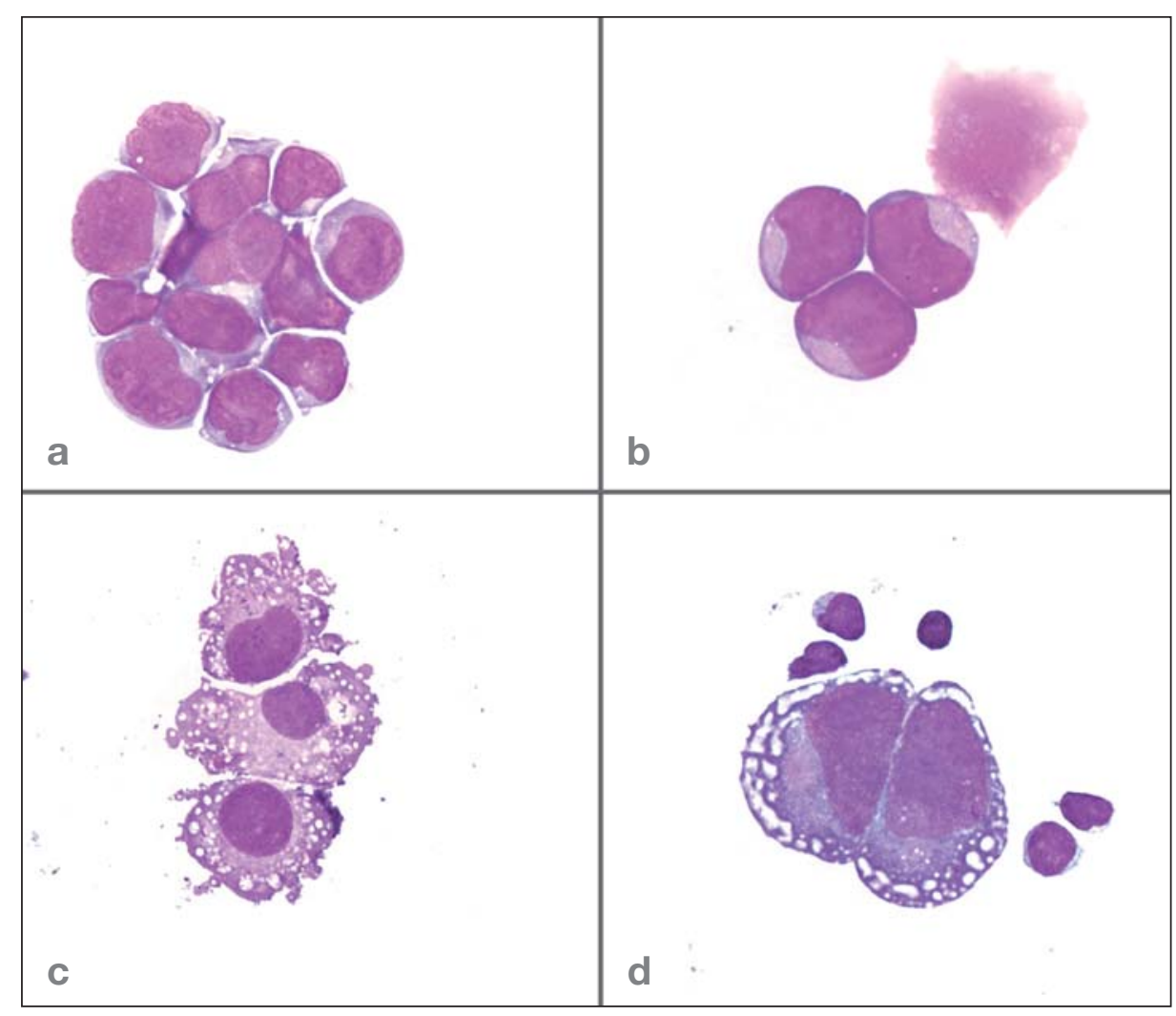

The central components of the SIOP LGG 2004 study are:

- Randomized intensification of chemotherapy with etoposide (in addition to vincristine/carboplatin)

- Prolongation of standard treatment (1.5 years vs. 1 year)

Because of the increased radiosensitivity, children with neurofibromatosis should, if possible, receive neither etoposide nor radiotherapy. Antiangiogenetic treatments have not yet progressed beyond the experimental stage (9). Changes in the BRAF signal pathway represent a promising approach (10).

The event-free and overall survival rates for children and adolescents treated with complete resection are excellent ( $80 \%$ to $90 \%)$ ). Patients with residual tumor after surgery are affected for a longer time, and may experience phases of tumor growth. These patients and other risk groups (non-resectable hypothalamic gliomas, diencephalic syndrome, and leptomeningeal metastases, among others) have much poorer prospects of long-term freedom from disease. According to recent studies the progression-free survival rate in children after treatment of LGG of the hypothalamus is $40 \%$ to $50 \%$. Close monitoring, particularly of vision, is essential (11).

\section{Medulloblastoma and cerebral primitive neuroectodermal tumor}

Medulloblastoma is the most frequent malignant brain tumor in childhood and adolescence. Postoperatively, patients without metastases undergo a 4-year course of irradiation followed by adjuvant chemotherapy. In the HIT'91 study, the 10-year survival rate was 91\% after complete resection but only $42 \%$ if macroscopic metastases were detected (12). The SIOP PNET-4 study sought to establish whether hyperfractionated irradiation is superior to conventional radiotherapy. The follow-up studies are investigating de-escalation of chemotherapy after irradiation in children classified as low risk. For the first time, the risk profile is being determined using molecular markers (low risk: no MYC amplification, beta catenin positive, no large-cell anaplastic histology [LCA], $<1.5 \mathrm{~cm}^{2}$ residual tumor). Intensification of the radiochemotherapy is being evaluated for patients with risk factors (MYC amplification, beta catenin negative, LCA, $>1.5 \mathrm{~cm}^{2}$ residual tumor, or other) (13).

Systemic and intraventricular chemotherapy has achieved good 5-year event-free survival (EFS) in neonates and infants, particularly those without residual tumor after operation (82\%) (14). For this reason, further attempts are being made to delay and reduce irradiation by means of high-dose methotrexate-based chemotherapy. It is intended to avoid radiotherapy altogether in children whose tumors exhibit favorable histology, e.g., desmoplastic and extensive nodular medulloblastomas. Children with primary metastases will receive intensified chemotherapy, and once they have achieved remission their treatment will be consolidated with high-dose chemotherapy (15). 
Kool et al. demonstrated that medulloblastomas can be classified into distinct prognosis groups according to molecular biological clinical, and histological criteria (13). The results in children with a Primitive neuroectodermal tumor (PNET) of the CNS are poorer than in those with medulloblastoma (16).

\section{Ependymomas}

Most ependymomas in children and adolescents (WHO grade II or III) arise from the membranes coating the ventricles, but these tumors can also occur in the spine. The primary aim of treatment is local tumor control by means of complete resection and postoperative irradiation. In the HIT'91 study the 3-year EFS was $83 \%$ for children without residual tumor and $38 \%$ for those with incomplete resection (17). The benefit of chemotherapy has not yet been formally demonstrated, but it can be used to delay radiotherapy in young children. Using modern irradiation methods, even infants can be successfully treated with high doses of irradiation without severe adverse effects (18). In future, patients with residual tumor after operation will receive additional doses of irradiation as well as chemotherapy with vincristine, etoposide, and cyclophosphamide.

\section{Craniopharyngiomas}

Ideally, the definitive treatment for craniopharyngioma is complete microsurgical resection of the tumor with preservation of the optic pathway and the hypothalamic-hypophyseal structures. The 10-year EFS rate in children is $80 \%$ after complete resection but only $35 \%$ to $40 \%$ after incomplete tumor removal (19). Adjuvant radiotherapy is an option in the case of unfavorable location and residual tumor (e.g., chiasma or hypothalamus). Since 2007 a randomized study has been analyzing whether prophylactic irradiation of progressive residual tumor is superior to interventional radiotherapy in children over 5 years of age. Quality of life and health status are being evaluated. Endocrinological and ophthalmological follow-up are essential.

\section{High-grade gliomas}

Both in Germany and internationally, treatment plans based on radiotherapy and temozolomide as standard have gained widespread acceptance for WHO grade III anaplastic astrocytoma, WHO grade IV glioblastoma, and other malignant gliomas. Other promising approaches include vaccination strategies and the administration of small-molecular compounds such as cediranib or cilengitide (20). Since glioblastomas in children differ in molecular structure from those in adults, there is only limited justification for adopting adult therapeutic strategies without any modification.

Data from the HIT-GBM studies show that patients with complete tumor resection have a much better chance of long-term survival (21). Despite improvement in survival times, the likelihood of eventual cure in children with residual or recurrent tumor is less than $5 \%$.

\section{Classification of CNS tumors (modi- fied from the Chang classification of medulloblastomas)}

- Tumor size and extent

T1 Diameter $<3 \mathrm{~cm}$; confined to cerebellar vermis, roof of fourth ventricle, or cerebellar hemisphere

T2 Diameter $\geq 3 \mathrm{~cm}$; infiltrating one neighboring structure or partially filling fourth ventricle

T3 a) Infiltrating two neighboring structures or completely filling fourth ventricle

T3 b) Additional infiltration of brain stem or floor of fourth ventricle

T4 Extending to midbrain/third ventricle or to upper cervical medulla

\section{- Metastasis}

M0 No sign of metastases

M1 Microscopic demonstration of tumor cells in CSF

M2 Macroscopic metastases in cerebellar/cerebral subarachnoid space or in supratentorial ventricles

M3 Macroscopic metastases in spinal subarachnoid space

M4 Metastases beyond the CNS

Children with a diffuse intrinsic pontine tumor (radiologically $>50 \%$ of the diameter of the pons) represent a special case. In the short term they benefit from radiotherapy, sometimes combined with adjuvant chemotherapy, but they usually die within 8 to 14 months (22).

\section{Germ cell tumors}

Germ cell tumors are found in the pineal gland or in a suprasellar location ( $20 \%$ bifocal). In secreting germcell tumors the tumor markers alpha fetoprotein (yolk sac tumors) and beta HCG (chorionic carcinomas) are used for diagnosis and monitoring, whereas germinomas require histological confirmation unless they exhibit the typically bilocular appearance (suprasellar and pineal). Treatment with platinum-containing chemotherapy (cisplatin, etoposide, ifosfamide) and local radiotherapy helps to avoid craniospinal irradiation and the associated complications. The latter is, however, indicated in disseminated disease. Mature teratomas do not respond to non-surgical treatment. One future strategy will be stratification of tumors according to metastasis and the level of the tumor marker alpha fetoprotein (23). 


\section{Atypical teratoid/rhabdoid tumors}

According to registry data, the most commonly occurring malignant tumors of the CNS in children under 6 months of age are atypical teratoid/rhabdoid tumors (AT/RT). Each year around 15 to 20 children are diagnosed with AT/RT in Germany. Intensive multimodal therapy including early radiotherapy has improved the 2-year overall survival rate from under $20 \%$ to $50-60 \%$, albeit at the cost of marked adverse effects (24). Modern forms of radiotherapy such as proton therapy will play an increasing role, especially in young children. All AT/RT seem to feature a change in the tumor suppressor gene SMARCB1/INI1, distinguishing them from cerebral PNET and other CNS malignancies. Therefore, experimental approaches have been devised to evaluate therapeutic intervention in epigenetic regulation of gene expression. European children with AT/RT are recorded in the EU-RHAB registry, the aim of which is to collate the epidemiological and molecular data across the continent and evaluate new treatments.

\section{Plexus tumors}

Because this entity is so rare, all children in the world diagnosed with a tumor of the choroid plexus are enrolled in the SIOP CPT 2000 study. For benign plexus papillomas and completely resected atypical plexus papillomas, surgery can be followed by vigilant observation; tumor cells in the CSF, incomplete resection, and plexus carcinoma warrant chemotherapy, however, followed in children over 3 years old by radiotherapy.

The 5-year overall and event-free survival rates are currently $59 \%$ and $37 \%$ respectively (25). The decisive prognostic factors are complete surgical resection and administration of radiotherapy.

\section{Late complications}

The proportion of children cured of CNS tumors has risen steadily in recent years. Many patients, however, suffer severe disease- or treatment-related problems, including neurological (paresis, ataxia, coordination deficits), neuropsychological (intelligence, concentration, perseverance), endocrine (short stature, delayed puberty), ophthalmological, and other disorders. Despite the good subjective quality of life, survivors often have problems with social integration, e.g., at school and in occupational training or at home with partner and family.

In order to identify and avoid these limitations in ongoing and future treatment optimization studies, children treated for CNS tumors should be followed up into adolescence and adulthood, with regular structured examinations to evaluate major neurological, neuropsychological, endocrine, and internal medicine functions. The HIT Treatment Network incorporates a basic diagnostic tool, available to researchers from all participating studies, for recording neuropsychological deficits.
The following treatment optimization studies and reference centers contributed data to this review:

HIT-2000, Hamburg (S. Rutkowski)

HIT REZ, Bonn (G. Fleischack)

EU-RHAB, Augsburg (M. Frühwald)

HIT HGG Halle (C. Kramm)

SIOP LGG 2004, Augsburg (A. Gnekow)

SIOP CNS GCT, Münster (G. Calaminus)

Craniopharyngeoma 2007, Oldenburg (H. Müller)

SIOP CPT, Hamburg (U. Kordes)

Biometrics, Mainz (A. Faldum)

Radiotherapy, Leipzig (R. Kortmann)

Neuropathology, Bonn (T. Pietsch)

Neuroradiology, Würzburg (M. Warmuth-Metz)

The HIT network receives financial support from the German Childhood Cancer Foundation (Deutsche Kinderkrebsstiftung).

\section{Acknowledgments}

We dedicate this review to our teachers Niels Sörensen and the late Joachim Kühl, the founding fathers of German pediatric neuro-oncology. We are profoundly grateful to Monika Warmuth-Metz (neuroradiology), Katharina Petrasch, Hermann Girschick, Hermann Müller, and Holger Ottensmeier (pediatric oncology) for their fundamental contributions to the HIT Task Force.

\section{Conflict of interest statement}

The authors declare that no conflict of interest exists.

Manuscript received on 18 February 2010, revised version accepted on 15 June 2010.

Translated from the original German by David Roseveare.

\section{REFERENCES}

1. Louis DN, Ohgaki H, Wiestler OD, et al.: The 2007 WHO Classification of Tumours of the Central Nervous System. Acta Neuropathol (Berl) 2007; 114: 97-109.

2. Wilne S, Collier J, Kennedy C, Koller K, Grundy R, Walker D: Presentation of childhood CNS tumours: a systematic review and metaanalysis. Lancet Oncol 2007; 8(8): 685-95.

3. Frühwald MC. Medulloblastoma. In: Schwab M, editor. Encyclopedic Reference of Cancer. Berlin: Springer 2008; 537-9.

4. Rudin CM, Hann CL, Laterra J, et al.: Treatment of medulloblastoma with hedgehog pathway inhibitor GDC-0449. N Engl J Med 2009; 361(12): 1173-8.

5. Warmuth-Metz M, Bison B, Leykamm S: Neuroradiologic Review in Pediatric Brain Tumor Studies. Klin Neuroradiol 2009; 21: 21.

6. Langen K-J, Tatsch K, Grosu A-L, Jacobs AH, Weckesser M, Sabri 0 : Diagnostics of cerebral gliomas with radiolabeled amino acids [Diagnostik von Hirntumoren mit radioaktiv markierten Aminosäuren]. Dtsch Arztebl Int 2008; 105(4): 55-61.

7. Sofou K, Kristjansdottir R, Papachatzakis NE, Ahmadzadeh A, Uvebrant $P$ : Management of prolonged seizures and status epilepticus in childhood: a systematic review. J Child Neurol 2009; 24(8): 918-26.

8. Creutzig U, Henze G, Bielack S, et al.: Krebserkrankungen bei Kindern. Erfolg durch einheitliche Therapiekonzepte seit 25 Jahren. Dtsch Arztebl 2003; 100(13): A 842-52.

9. Packer RJ, Jakacki R, Horn M, et al.: Objective response of multiply recurrent low-grade gliomas to bevacizumab and irinotecan. Pediatr Blood Cancer 2009; 52(7): 791-5.

10. Pfister S, Janzarik WG, Remke M, et al.: BRAF gene duplication constitutes a mechanism of MAPK pathway activation in low-grade astrocytomas. J Clin Invest 118(5): 1739-49.

11. Gnekow AK, Kortmann RD, Pietsch T, Emser A: Low grade chiasmatic-hypothalamic glioma-carboplatin and vincristin chemotherapy effectively defers radiotherapy within a comprehensive treatment strategy - report from the multicenter treatment study for children and adolescents with a low grade glioma-HIT-LGG 1996 — of the Society of Pediatric Oncology and Hematology (GPOH). Klin Padiatr 2004; 216(6): 331-42.

12. von Hoff K, Hinkes B, Gerber NU, et al.: Long-term outcome and clinical prognostic factors in children with medulloblastoma treated in the prospective randomised multicentre trial HIT'91. Eur J Cancer 2009; 45(7): 1209-17. 
13. Kool M, Koster J, Bunt J, et al.: Integrated genomics identifies five medulloblastoma subtypes with distinct genetic profiles, pathway signatures and clinicopathological features. PLoS One 2008; 3(8): e3088.

14. Rutkowski S, Bode U, Deinlein F, et al.: Treatment of early childhood medulloblastoma by postoperative chemotherapy alone. $N$ Engl J Med 2005; 352(10): 978-86.

15. Rutkowski S, Cohen B, Finlay J, et al.: Medulloblastoma in young children. Pediatr Blood Cancer 2010; 54: 635-7.

16. Timmermann B, Kortmann RD, Kuhl J, et al.: Role of radiotherapy in the treatment of supratentorial primitive neuroectodermal tumors in childhood: results of the prospective German brain tumor trials HIT 88/89 and 91. J Clin Oncol 2002; 20(3): 842-9.

17. Timmermann B, Kortmann RD, Kuhl J, et al.: Combined postoperative irradiation and chemotherapy for anaplastic ependymomas in childhood: results of the German prospective trials HIT 88/89 and HIT 91. Int J Radiat Oncol Biol Phys 2000; 46(2): 287-95.

18. Merchant TE, Li C, Xiong X, Kun LE, Boop FA, Sanford RA: Conformal radiotherapy after surgery for paediatric ependymoma: a prospective study. Lancet Oncol 2009; 10(3): 258-66.

19. Muller HL: Childhood craniopharyngioma. Recent advances in diagnosis, treatment and follow-up. Horm Res 2008; 69(4): 193-202.

20. De Vleeschouwer S, Fieuws S, Rutkowski S, et al.: Postoperative adjuvant dendritic cell-based immunotherapy in patients with relapsed glioblastoma multiforme. Clin Cancer Res 2008; 14(10): 3098-104.
21. Wolff JE, Driever PH, Erdlenbruch B, et al.: Intensive chemotherapy improves survival in pediatric high-grade glioma after gross total resection: results of the HIT-GBM-C protocol. Cancer 2009; 2: 2.

22. Wagner S, Warmuth-Metz M, Emser A, et al.: Treatment options in childhood pontine gliomas. J Neurooncol 2006; 79(3): 281-7.

23. Calaminus G, Bamberg M, Harms D, et al.: AFP/beta-HCG secreting CNS germ cell tumors: long-term outcome with respect to initial symptoms and primary tumor resection. Results of the cooperative trial MAKEI 89. Neuropediatrics 2005; 36(2): 71-7.

24. Chi SN, Zimmerman MA, Yao X, et al.: Intensive multimodality treatment for children with newly diagnosed CNS atypical teratoid rhabdoid tumor. J Clin Oncol 2008; 8(5): 8-14.

25. Mazloom A, Wolff JE, Paulino AC: The impact of radiotherapy fields in the treatment of patients with choroid plexus carcinoma. Int $J$ Radiat Oncol Biol Phys 2009; 8: 8.

\section{Corresponding author}

Prof. Dr. Dr. med. Michael C. Frühwald

I. Klinik für Kinder und Jugendliche

Klinikum Augsburg

Stenglinstr. 2

86156 Augsburg, Germany

Michael.Fruehwald@Klinikum-Augsburg.de

@

eTables available at

www.aerzteblatt-international.de/11m0390 


\section{Tumors of the Central Nervous System in Children and Adolescents}

Michael C. Frühwald, Stefan Rutkowski

\begin{tabular}{|c|c|c|c|}
\hline \multicolumn{4}{|c|}{ Molecular changes in CNS tumors of childhood and adolescence } \\
\hline Entity & Molecular genetics & $\begin{array}{l}\text { Target } \\
\text { structure }\end{array}$ & Compound \\
\hline Medulloblastoma & $\begin{array}{l}\text { LOH 1, 9, 10, 11, 16, } 17 \\
\text { Amplification MYC, MYCN } \\
\text { Mutation PTCH1, 2, WNT, } \\
\text { SMOH, ATOH, SUFUH, } \\
\text { B-catenin } \\
\text { ERBB2 overexpression } \\
\text { Epigenetics }\end{array}$ & $\begin{array}{l}\text { SHH } \\
\text { ERBB2 }\end{array}$ & $\begin{array}{l}\text { Cyclopamine } \\
\text { GDC-0449 } \\
\text { Cetuximab } \\
\text { MK0752 }\end{array}$ \\
\hline CPNET & $\begin{array}{l}\text { LOH 1q, } 5 p, 5 q, 6 p, 14 q \\
\text { Epigenetics }\end{array}$ & & \\
\hline Ependymoma & $\begin{array}{l}\text { LOH 22q, gain 1q; hTERT, } \\
\text { EGFR overexpression; } \\
\text { mutation NF1 }\end{array}$ & & \\
\hline AT/RT & $\begin{array}{l}\text { Mutation SMARCB1; } \\
\text { epigenetics }\end{array}$ & CDK1 & Flavopiridol \\
\hline HGG & $\begin{array}{l}\text { LOH 9p, 10, 13q, 17p; } \\
\text { mutation EGFR, TP53, } \\
\text { CDK4, PDGFR } \\
\text { Amplification EGFR, MDM2 } \\
\text { p16 loss }\end{array}$ & $\begin{array}{l}\text { EGFR PDGFR } \\
\text { FT }\end{array}$ & $\begin{array}{l}\text { Antibodies } \\
\text { FTI } \\
\text { TKI }\end{array}$ \\
\hline $\begin{array}{l}\text { Pilocytic astrocyto- } \\
\text { mas }\end{array}$ & $\begin{array}{l}\text { Mutation } N F 1 \text {; } \\
\text { trisomy } 7,8 ; \\
\text { BRAF mutation }\end{array}$ & BRAF & TKI \\
\hline Gangliogliomas & TSC2? & & \\
\hline CPT & $\begin{array}{l}\text { Mutation TP53; } \\
\text { 9p additional copies } \\
\text { MGMT methylation }\end{array}$ & & \\
\hline
\end{tabular}

$\mathrm{FT}$, farnesyl transferases; FTI, farnesyl transferase inhibitors; TKI, tyrosine kinase inhibitors 


\section{eTABLE 2}

\section{Familial syndromes frequently associated with CNS tumors}

\begin{tabular}{|c|c|c|}
\hline Syndrome & $\begin{array}{l}\text { Gene (chrom. } \\
\text { locus) }\end{array}$ & Tumor diagnosed \\
\hline Li-Fraumeni & TP53 (17p13) & $\begin{array}{l}\text { Astrocytomas }\left(I^{\circ}-\mathrm{V}^{\circ}\right) ; \mathrm{cPNET} \text {; } \\
\text { medulloblastoma, CPT }\end{array}$ \\
\hline $\begin{array}{l}\text { BTPS I or Turcot I } \\
\text { (with HNPCC) }\end{array}$ & $\begin{array}{l}\text { hMLH1 (3p21) } \\
\text { hPMS2 (7p22) }\end{array}$ & $\begin{array}{l}\text { Glioblastoma (rarely astrocyto- } \\
\text { mas II und III, oligodendroglio- } \\
\text { mas) }\end{array}$ \\
\hline $\begin{array}{l}\text { BTPS II or Turcot II } \\
\text { (with FAP) }\end{array}$ & $A P C(5 q 21)$ & Medulloblastoma \\
\hline RTPS & $\begin{array}{l}\text { SMARCB1 } \\
(22 q 11.2)\end{array}$ & $\begin{array}{l}\text { AT/RT, extracranial rhabdoid } \\
\text { tumors }\end{array}$ \\
\hline Cowden & PTEN (10q23) & $\begin{array}{l}\text { Dysplastic cerebellar ganglio- } \\
\text { cytoma (Lhermitte-Duclos) }\end{array}$ \\
\hline Familial retinoblastomas & $R B 1(13 q 14)$ & Retinoblastomas \\
\hline \multicolumn{3}{|c|}{ Phacomatoses (neurocutaneous syndromes) } \\
\hline Tuberous sclerosis & $\begin{array}{l}\text { TSC1 (9q34) } \\
\text { TSC2 (16p13) }\end{array}$ & $\begin{array}{l}\text { Subependymal giant cell astro- } \\
\text { cytomas (SEGA), subependymal } \\
\text { hamartomas, cortical tubers }\end{array}$ \\
\hline von Hippel-Lindau & VHL (3p25) & Hemangioblastoma \\
\hline Neurofibromatosis 1 & $N F 1(17 q 11)$ & $\begin{array}{l}\text { Optic pathway glioma and other } \\
\text { astrocytomas, neurofibromas, } \\
\text { MPNST }\end{array}$ \\
\hline Neurofibromatosis 2 & $N F 2(22 q 12)$ & $\begin{array}{l}\text { Bilateral vestibular schwanno- } \\
\text { mas, peripheral schwannomas, } \\
\text { meningiomas, meningiomatosis, } \\
\text { astrocytomas, spinal ependymo- } \\
\text { mas, glial hamartomas }\end{array}$ \\
\hline NBCCS (Goltz-Gorlin) & PTCH (9q31) & $\begin{array}{l}\text { Medulloblastomas (rarely } \\
\text { meningiomas) }\end{array}$ \\
\hline
\end{tabular}

BTPS, brain tumor polyposis syndrome; CPT, choroid plexus tumor NBCCS, nevoid basal cell carcinoma syndrome; RTPS: rhabdoid tumor predisposition syndrome 